\title{
Synthesis and characterization of rubbery epoxy/organoclay hectorite nanocomposites
}

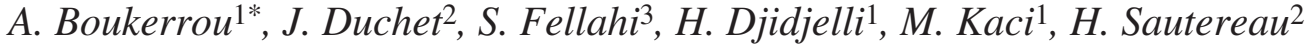 \\ ${ }^{1}$ Laboratoire des Matériaux Organiques, Université Abderrahmane Mira, Bejaia 06000, Algeria \\ 2Laboratoire des Matériaux Macromoléculaires de l'INSA de Lyon, 20 Avenue Albert Einstein, \\ 69621 Villeurbanne-Lyon, France \\ ${ }^{3}$ Département de Génie des Polymères, Institut Algérien du Pétrole (IAP) de Boumerdès 35000, Algeria
}

Received 2 September 2007; accepted in revised form 6 November 2007

\begin{abstract}
The present research investigates the morphology, the mechanical, and the viscoelastic properties of rubbery epoxy/clay nanocomposites synthesized by in situ polymerisation of a prepolymer diglycidyl ether of bisphenol-A crosslinked with an aliphatic diamine based on a polyoxypropylene backbone. The inorganic phase was hectorite, exchanged with octadecylammonium ions in order to give organophilic properties to the phyllosilicate. An ultrasonicator was used to disperse the silicate clay layer into epoxy-amine matrix. The morphology of epoxy-hectorite nanocomposites examined by transmission electron microscopy (TEM) showed that mixed delamination or intercalation or microdispersion could occur depending on type of organoclay. Moreover, the mechanical and viscoelastic properties were found to be improved with only the treated hectorite.
\end{abstract}

Keywords: nanocomposites, epoxy, hectorite, organoclay

\section{Introduction}

The utility of using nanosize layered silicate (organically modified clays) as reinforcements in organic polymers to obtain polymer/clay nanocomposites has been well reported over the past decade [1]. Good improvement in properties can be achieved in such materials due to the high surface contact area of he reinforcing filler which causes high strength, modulus and other properties at low clay loading level usually $(<5 \mathrm{wt} \%)$. Our work is aimed to study epoxy-hectorite nanocomposites due to the wide applications of epoxy prepolymers as structural matrices and adhesives in electronic, electrical products and other items [1]. Therefore, epoxy prepolymers are some of the most commonly studied polymers in the preparation of nanocomposites with layered silicates because the polar epoxy monomers can easily diffuse into the clay galleries $[2,3]$. In fact, the matrix/filler type system used, the extent of filler adhesion to the matrix, and the levels of dispersion of the filler throughout the matrix degree are among the parameters which mainly determine any enhancement of a particular property of nanocomposites [4]. Moreover, the nature of the surfactant as well as the curing conditions, especially the temperature is expected to play a role in the exfoliation process [2]. In this respect, Kornman et al. [5] reported recently that a long chain alkylamine, having a chain of more than eight carbon atoms, could significantly result in an exfoliated clay structure. Furthermore, a balance between the intragallery and extragallery polymerization rates is essential to exfoliate the clay in an epoxy system [6]. According to the literature data [7-12], there are three different methods to synthesize polymer-clay nano-

*Corresponding author, e-mail: aboukerrou@yahoo.fr

(c) BME-PT and GTE 
composites: melt intercalation process for thermoplastic polymers, solution method, where both organoclay and polymer precursors are dissolved in a polar organic solvent and in situ polymerization technique. However, the latter one was found to be the most effective technique for thermoset polymer matrix nanocomposites [6].

On the other hand, the commonly used techniques for processing clay-epoxy nanocomposites are direct mixing and solution mixing [13]. However, these techniques produce intercalated or intercalated/exfoliated composites rather than exfoliated composites. According to Vaia et al. [14], the degree of exfoliation can be improved through the aid of conventional shear devices such as extruders, mixers, ultrasonicators, etc.

In this paper, ultrasonication was used as a means of applying external shearing forces to disperse and exfoliate the silicate clay layers in the epoxy matrix. The procedure consisted firstly of swelling the clays in the curing agent due to its low viscosity allowing better diffusion into the intragallery space. The epoxy prepolymer was added, and under these conditions, the occurrence of a complete exfoliation was expected. It is worthwhile to point out that the nanosilicate used to carry out this study was a natural hectorite (called HECT) because literature data on its application in the epoxy-nanocomposites system are rather scarce.

\section{Experimental}

\subsection{Materials used}

The clay was a natural hectorite (called HECT) supplied by Süd-Chemie (from Germany) whose trade name is Optigel SH. It was a sodic silicate containing mainly magnesium and lithium according to the following chemical formula:

$\mathrm{Na}_{0.32}\left(\mathrm{Mg}_{2.82} \mathrm{Li}_{0.18}\right) \mathrm{Si}_{4} \mathrm{O}_{10}(\mathrm{OH})_{2}$.

The cation exchange capacity (CEC) of the clay was $120 \mathrm{mequ} / 100 \mathrm{~g}$.

The organic system was based on epoxy/amine, the prepolymer diglycidyl ether of bisphenol A (DGEBA) is manufactured by Vantico (France) under the grade name DGEBA LY 556 with the following characteristics: an $n$ (polymerization degree) value of 0.15 and a number-average molecular weight of $382.6 \mathrm{~g} / \mathrm{mol}$. The curing agent is an aliphatic diamine with a polyoxypropylene backbone supplied by Huntsman (Belgium) under the trade name Jeffamine D2000 with a number-average molecular weight of $1970 \mathrm{~g} / \mathrm{mol}$.

\subsection{Organoclay preparation}

The method of organoclay preparation is similar to that used by Le Pluart et al. [7]. The silicates were exchanged with octadecylammonium ions at $80^{\circ} \mathrm{C}$ with two CEC's (cation exchange capacity) amine/ clay ratio. 0.2 moles of octadecylamine were dissolved in 201 of $0.01 \mathrm{~N}$ of hydrochloric acid solution (based on deionised water). The solution was stirred at $80^{\circ} \mathrm{C}$ for three hours. Then, $100 \mathrm{~g}$ of clay were added to the solution and the whole was stirred at the same temperature for three more hours. The solution was filtered and the silicates were further washed 6 times more with hot deionised water and once with a hot ethanol: water (1:1) mixture so that no chloride was detected up on adding $0.1 \mathrm{~m}$ aqueous $\mathrm{AgNO}_{3}$.

The resulting organoclay was then dried at $85^{\circ} \mathrm{C}$ for 36 hours and kept dry in a vacuum box. After modification, the organomodified silicates are called HECTC18.

\subsection{Preparation of epoxy-nanocomposites}

The silicate clays 5 per hundred resin $(5 \mathrm{phr})$ and the curing agent were initially sonicated at $80^{\circ} \mathrm{C}$ for $10 \mathrm{~min}$ using an ultrasonic processor device at a frequency of $20 \mathrm{kHz}$, an amplitude of $6 \mu \mathrm{m}$ and electric power of 130 watts. The temperature of $80^{\circ} \mathrm{C}$ corresponded to the first curing temperature of the reactive agents. The epoxy prepolymer was then added to the mixture, and the whole was stirred for $15 \mathrm{~min}$ more. Then, the blend was poured into a steel mold and cured for 2 hours at $80^{\circ} \mathrm{C}$, this was followed by postcuring for 3 hours at $120^{\circ} \mathrm{C}$. The stoichiometric mass ratio of DGEBA to D2000 was calculated, and the value was 2.65 according to the the diamine functionality, which was itself determined by chlorydric acid in dioxane (3.54) [15].

\subsection{Nanocomposite characterization}

\subsubsection{Wide angle $X$-ray diffraction}

Wide angle X-ray diffraction (WAXD) measurements were performed at room temperature on a SIEMENS D500 diffractometer ( Germany) with a Brentano Bragg geometry goniometer with $\mathrm{CuK}_{\alpha}$ 
radiation (wavelength $=1.54 \AA$ ), operating at $40 \mathrm{kV}$ and $30 \mathrm{~mA}$. The diffraction patterns were collected between angles $2 \theta$ of 1 and $70^{\circ}$ for unmodified HECT and $1-10^{\circ}$ for modified HECT, at a scanning rate and step size of $5 \% \mathrm{~min}$ and $0.02^{\circ}$, respectively.

\subsubsection{Transmission electronic microscopy}

The different nanocomposites samples were ultramicrotomed with a diamond knife on a Leica (Bannock-burn IL) Ultracut UCT microtome at $-70^{\circ} \mathrm{C}$ to give sections with a nominal thickness of $70 \mathrm{~nm}$. The sections were transferred from dry conditions $\left(-70^{\circ} \mathrm{C}\right)$ to carbon-coated $200-$ mesh $\mathrm{Cu}$ grids. The transmission electronic microscopy (TEM) images were obtained at $120 \mathrm{kV}$ under low dose conditions, with a Philips CM120 electron microscope (Netherlands).

\subsubsection{Tensile testing}

The stress - strain parameters were measured according to NF T 51-034 method, on a tensile machine 2/M which belongs to the MTS Society (France). The specimen has the shape H3 having the dimensions $2 \times 4 \times 10 \mathrm{~mm}$, while the measurements were carried out at room temperature with a crosshead speed of $5 \mathrm{~mm} / \mathrm{min}$. An average value of 5 samples was determined.

The theory of rubber elasticity [16] was used to relate the state of deformation at the molecular level to the externally applied deformation. In the case of uniaxial deformation, the true stress (force divided by the deformed area) is defined, for dry networks formed in the bulk state as Equation (1):

$\sigma=\rho \frac{R T}{M_{c}} \cdot\left(\lambda^{2}-\lambda^{-1}\right)$

where $\sigma$ is the true stress, $\rho$ is the network density, $T$ is the absolute temperature, $M_{c}$ is the average molecular weight of chains between crosslinks and $\lambda$ is the extension ratio defined as the ratio of the final length of the sample in the direction of stretch to the initial length before deformation.

\subsubsection{Dynamic mechanical thermal analysis}

The dynamic mechanical thermal analysis of the nanocomposite properties was determined with a Rheometric Dynamic Analyzer (Paris, France). The tests were carried out in the torsion deformation mode, at a frequency of $1 \mathrm{~Hz}$, with a temperature program ranging from -100 to $50^{\circ} \mathrm{C}$ at a heating rate of $3{ }^{\circ} \mathrm{C} / \mathrm{min}$ under a controlled strain of $0.17 \%$ corresponding to the linear portion of the viscoelastic domain of the material.

\section{Results and discussion}

\subsection{Organophilic modification of hectorite}

The X-ray diffraction spectra gathered in Figure 1 already reveals that a first peak located on the spectrum characterizes the repetition of platelet in the direction (001), i. e. d-spacing and the other peaks allow to identify the silicate host structure. Although hectorite is a natural silicate, the diffraction peaks are less resolved. The shoulder at $12.03 \AA$ reveals the lack of platelet organization on long distances.

After the cationic exchange, the silicate surface properties are modified. Taking into account the lack of crystalline organization for pristine hectorite, it is impossible to characterize the intercalation of organic chains between hectorite platelets by WAXS (Figure 2).

The thermal stability of clay before modification, analyzed by TGA from the weight loss derivative $(\mathrm{d} m / \mathrm{d} T)$ as a function of the temperature, is reported in Figure 3. Three areas of weight loss on DTG curves can be observed. The first volatile departure at temperatures lower than $150^{\circ} \mathrm{C}$ is associated with the vaporization of free water (between

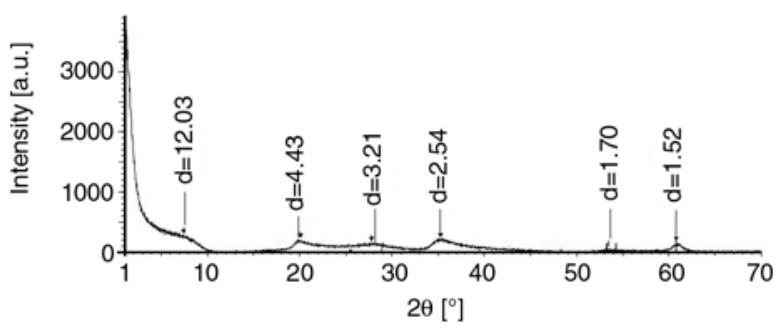

Figure 1. WAXD patterns of unmodified hectorite. The distance is given in $\AA$

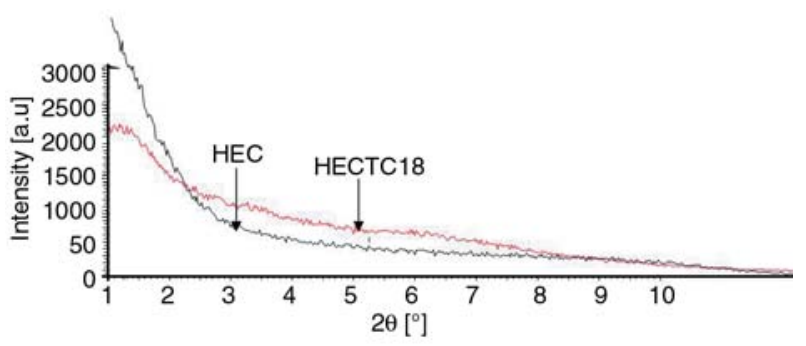

Figure 2. WAXD patterns of unmodified and modified hectorite. The distance is given in $\AA$ 


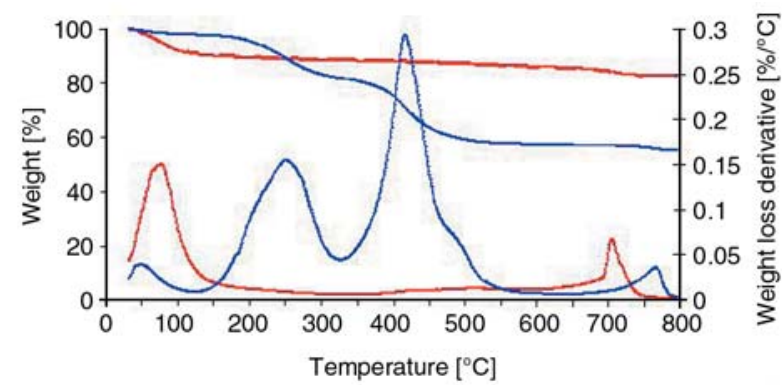

Figure 3. Weight loss and weight loss derivative of modified and unmodified hectorirte

pores and aggregates). The second area is attributed to departure of intercalated water on a temperature range included between 350 and $670^{\circ} \mathrm{C}$, and for higher temperatures between 650 and $750^{\circ} \mathrm{C}$, the dehydroxylation of silicates is observed [17].

In Figure 3, the thermogravimetric analysis (TGA) of clay after modification, reveals several peaks linked to a volatile departure. The low-temperature peak, located between 40 and $70^{\circ} \mathrm{C}$, is associated to the vaporization of free water and water bonded to the cations by hydrogen bonds. The following decompositions are related to alkylammonium ions. It was shown previously [17], that the first decomposition step is due to adsorbed octadecylammonium ions. In fact, after the cationic exchange, some ions remain adsorbed on hydroxyl groups on platelets edges and are not intercalated between the nanoplatelets. The thermal decomposition takes place in the range to $200-350^{\circ} \mathrm{C}$ range. The well intercalated modifying ions show higher thermal stability and the decomposition temperature included between $350-500^{\circ} \mathrm{C}$ depends on interactions between different organic groups and the platelet surface. At temperatures higher than $700^{\circ} \mathrm{C}$, the dehydroxylation of the silicates takes place [18]. Thus the organophilic clays display organic chains both inside galleries as intercalated species and outside platelets as adsorbed species. This later category could be a wettability aid of nanofillers for being introduced into organic medium. The cationic exchange capacity was measured from the amount of intercalated ions determined after careful washing and the value is $120 \mathrm{meq} / 100 \mathrm{~g}$ indicating the high intercalated ions ratio inside galleries. These results indicate clearly that the organic modification of HECT occurs by ion exchange of the sodium ions present on HECT with organic alkyl ammonium ions leading to an intercalation.

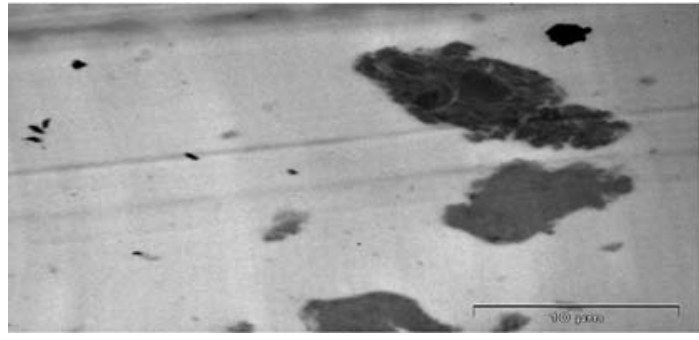

Figure 4. Transmission electronic microscopy (TEM) of DGEBA/D2000/HECT nanocomposites

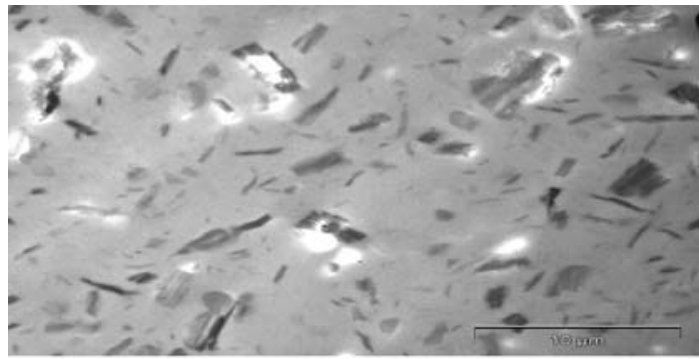

Figure 5. Transmission electronic microscopy (TEM) of DGEBA/D2000/HECTC18 nanocomposites

\subsection{Morphology}

Figures 4 and 5 show the transmission electron micrograph (TEM) images of HECT and HECTC18 nanocomposites, respectively. In Figure 5, it is observed the formation of agglomerates indicating clearly the poor dispersion of the clays in the epoxy matrix, because of the poor interactions between a polar unmodified HECT and the organic matrix. In contrast, Figure 5 illustrates a good dispersion of the clay particles and layers in the matrix resulting from the swelling of the HECTC18 in the nanocomposites, indicating a good compatibility between organophilic modified hectorite and the organic matrix [19].

\subsection{Mechanical properties}

Figure 6 shows the curves of the true stress as a function of $\left(\lambda^{2}-\lambda^{-1}\right)$ for HECT and HECTC18 nanocomposites. The general form of the curves fits a linear relationship that is described by the following equation: $\sigma=E\left(\lambda^{2}-\lambda^{-1}\right)$, where $E$ represents the slope of the curve defined as a rubber elasticity modulus [16]. In both samples, the stiffness is improved, however more pronounced in the case of HECTC18 nanocomposites. In fact, this property is increased by 16 and $55 \%$ for HECT and HECTC18 nanocomposites, respectively. This result is in agreement with that obtained by Wang et al. [20] who reported that the addition of $5 \mathrm{wt} \%$ 
Table 1. Mechanical properties of the nanocomposites based on the DGEBA/D2000 matrix. $E_{0}$, elastic modulus of the neat matrix, $\varepsilon_{r}$, elongation at break, $W_{0}$, energy at break of the neat matrix, $W_{b}$, energy at break of the nanocomposite, $\sigma_{r}$, stress at break. Those parameters were measured at $22^{\circ} \mathrm{C}$.

\begin{tabular}{|c|c|c|c|c|c|c|}
\hline Matrix DGEBA/D2000 & $\mathbf{E}[\mathbf{M P a}]$ & $\mathbf{E}_{\mathbf{E}} \mathbf{E}_{\mathbf{0}}$ & $\sigma_{\mathbf{r}}[\mathbf{M P a}]$ & $\varepsilon_{\mathbf{r}}[\boldsymbol{\%}]$ & $\mathbf{W}_{\mathbf{b}}\left[\mathbf{1 0}^{-\mathbf{3}} \mathbf{J}\right]$ & $\mathbf{W}_{\mathbf{b}} / \mathbf{W}_{\mathbf{0}}$ \\
\hline Unloaded & 0.51 & 1 & $0.8 \pm 0.05$ & $69 \pm 5$ & $26 \pm 2$ & 1 \\
\hline HECT $(5 \mathrm{phr})$ & 0.59 & 1.16 & $0.58 \pm 0.05$ & $10 \pm 3$ & $50 \pm 3$ & 1.92 \\
\hline HECTC18 (5 phr) & 0.79 & 1.55 & $1.03 \pm 0.07$ & $88 \pm 3$ & $118 \pm 2$ & 4.54 \\
\hline
\end{tabular}

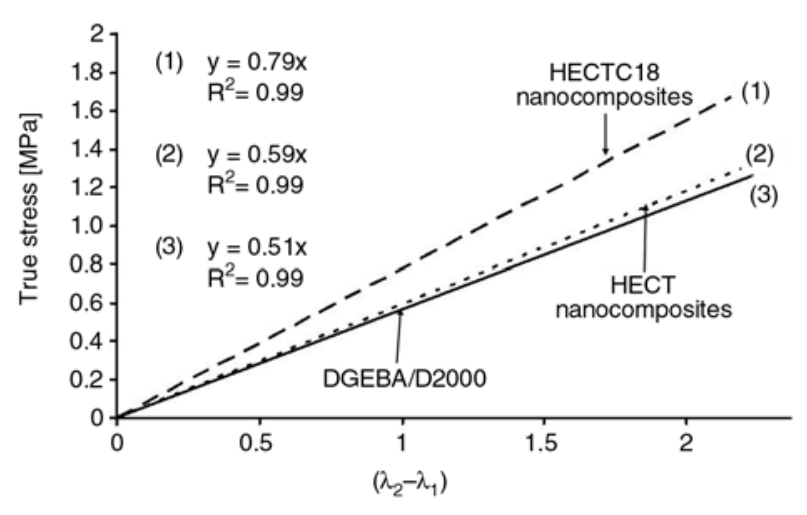

Figure 6. True stress as function of $\left(\lambda^{2}-\lambda^{-1}\right)$ of DGEBA/ D2000 matrix, HECT and HECTC18 nanocomposites

of nanoclay in epoxy amine matrix leads to an increase by twice of the rubber elasticity of the nanocomposites compared to that of the matrix.

The $E$ values are reported in details in Table 1 .

The stiffness, stress, strain and energy at break values of the epoxy matrix (DGEBA/D2000), HECT and HECTC18 nanocomposites are reported in details in Table 1. An increase of both the stress and the energy at break is observed in HECTC18 nanocomposite samples compared with the epoxy matrix. The increase of these two parameters could be attributed to better dispersion of organophilic nanosilicate in the nanocomposites compared to unmodified hectorite nanocomposites. These results are consistent with those obtained by TEM. When the dispersion of organoclays in the matrix DGEBA/ D2000 is carried out manually, the mechanical properties do not increase significantly, compared with the results obtained with ultrasound mixing process. The improvement of mechanical properties might be linked to the state of dispersion at the micron and the nanometer scale level [7].

\subsection{Dynamic thermal mechanical analysis}

The dynamic mechanical properties of HECT and HECTC18 nanocomposites have been studied over a wide range $\left(-100\right.$ to $\left.50^{\circ} \mathrm{C}\right)$. The variation of $\tan \delta$ as a function of temperature for both materials is

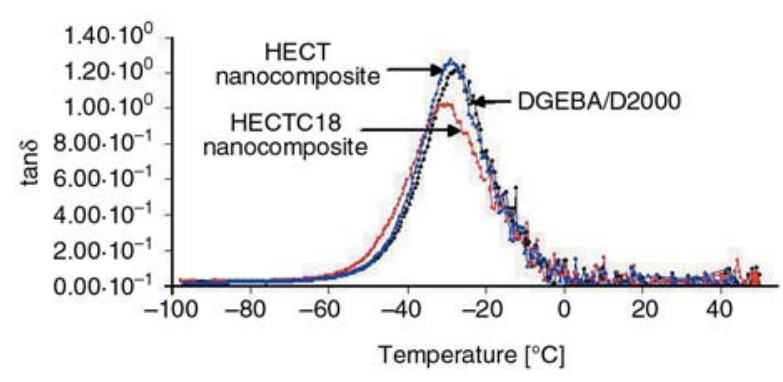

Figure 7. Tan $\delta$ as a function of temperature for DGEBA/ D2000 matrix, HECT and HECTC18 nanocomposites

reported in Figure 7. In this figure, it is observed one relaxation peak corresponding to the mechanical transition temperature which slightly decreases in the presence of the organosilicate. According to the literature [21], this behaviour is explained in terms of a reduction of the polymer volume fraction in the presence of the filler. This means that at low temperatures, the polymer matrix by itself is responsible for a high proportion of energy dissipation, while the nanoparticles strongly absorb any energy. Moreover, the tan $\delta$ peak seems to shift slightly to higher temperatures upon adding the nanoclay from -31 to $-29^{\circ} \mathrm{C}$. According to LopezManchado [22], these results are due to the occurrence of a strong adhesion between the nanoclay and the matrix. This interaction reduces the mobil-

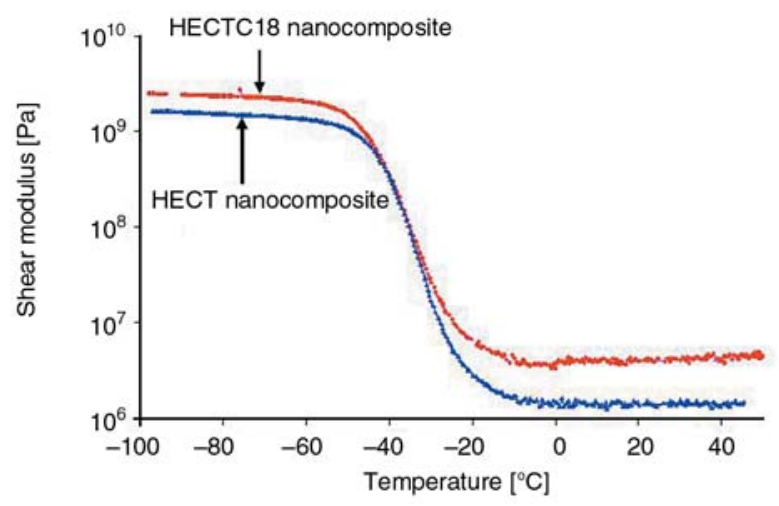

Figure 8. Storage modulus as a function of temperature for DGEBA/D2000 matrix, HECT and HECTC18 nanocomposites, measured at $1 \mathrm{~Hz}$ 
Table 2. Values of the shear modulus $\left(G^{\prime}\right)$, mechanical transition temperature $\left(T_{m}\right)$, and $\tan \delta$ of various samples based on DGEBA/D2000 matrix, HECT and HECTC18 nanocomposites recorded at $1 \mathrm{~Hz}$, measured between -100 and $50^{\circ} \mathrm{C}$

\begin{tabular}{|c|c|c|c|}
\hline Formulation codes & $\begin{array}{c}\mathbf{G}^{\prime} \text { at } \mathbf{2 5}^{\circ} \mathbf{C} \\
{[\mathbf{M P a}]}\end{array}$ & $\begin{array}{c}\mathbf{T}_{\mathbf{m}} \\
{\left[{ }^{\circ} \mathbf{C}\right]}\end{array}$ & $\tan \delta$ \\
\hline DGEBA/D2000 & 1.23 & -31 & 1.2 \\
\hline HECT/DGEBA/D2000 & 1.30 & -30 & 1.1 \\
\hline HECTC18/DGEBA/D2000 & 4.26 & -29 & 1.0 \\
\hline
\end{tabular}

ity of the rubber epoxy chains, resulting in elevated transition temperature.

Figure 8 shows the shear modulus of HECT and HECTC18 nanocomposites as a function of temperature. It is noted that the organoclay induces a slight increase in modulus value of HECTC18 nanocomposites compared with the epoxy matrix witch is attributed to the interaction of epoxy and HECTC18 [23]. All the data are reported in details in Table 2.

\section{Conclusions}

From the study, the following conclusions can be drawn. Hectorite is a natural silicate, the diffraction peaks are less resolved. The shoulder at $12.03 \AA$ reveals the lack of platelet organization on long distances.

The modification of the surface of HECT by octadecylammonium ions to HECTC18 produces an intercalation as demonstrated by the TG/DTG thermograms. The addition of HECTC18 to the epoxy matrix in the proportion of $5 \mathrm{phr}$ and the application of a sonicator as a device to ensure a good stirring leads to an exfoliation. As a result, a significant improvement of both the stress - strain parameters at break and the viscoelastic properties is observed. Finally, the HECTC18 increases considerably both the stiffness and the energy at break of the nanocomposites, although it is not easy to obtain a compromise between the two parameters. However, in the case of the nanocomposites studied, i. e. DGEBA/D2000/HECTC18, the homogeneity of the morphology results in a significant increase of both the stiffness by almost 55\% and the energy at break by more than $350 \%$.

\section{References}

[1] Boukerrou A., Duchet J., Fellahi S., Sautereau H.: Effect of geomerty and surface properties of silicates on nanostructuration of suspension in precursors of an epoxy/amine network. Journal of Applied Polymer Science, 102, 1380-1390 (2006).

[2] Kornmann X., Lindberg H., Berglund L. A.: Synthesis of epoxy-clay nanocomposites. Influence of the nature of the curing agent on structure. Polymer, 42, 44934499 (2001).

[3] Chin I-J., Thurn-Albrecht T., Kim H-C., Russel T. P., Wang J.: On exfoliation of montmorillonite in epoxy. Polymer, 42, 5947-5952 (2001).

[4] Evora V. M. F., Shukla A.: Fabrication, characterization and dynamic behavior of polyester/ $/ \mathrm{TiO}_{2}$ nanocomposites. Material Science and Engineering: A, 363, 358-366 (2003).

[5] Kornmann X., Lindberg H., Berglund L. A.: Synthesis of epoxy-clay nanocompsites: Influence of the nature of the clay on the structure. Polymer, 42, 1303-1310 (2001).

[6] Nigam V., Setua D. K., Matur G. N., Kar K. K.: Epoxy-montmorillonite clay nanocomposites: Synthesis and characterization. Journal of Applied Polymer Science, 93, 2201-2210 (2004).

[7] Le Pluart L., Duchet J., Sautereau H.: Epoxy/montmorillonite nanocomposites: Influence of organophilic traitment on reactivity, morphology and fracture properties. Polymer, 46, 12267-12278 (2005).

[8] Chow W. S.: Water absorption of epoxy/glass fiber/ organo-montmorillonite nanocomposites. Express Polymer Letters, 1, 104-108 (2007).

[9] Pegoretti A., Dorigato A., Penati A.: Tensile mechanical response of polyethylene-clay nanocomposites. Express Polymer Letters, 1, 123-131 (2007).

[10] Da Z. L., Zhang Q. Q., Wu D. M., Yang D. Y., Qiu F. X.: Synthesis, characterization and thermal properties of inorganic-organic hybrid. Express Polymer Letters, 1, 698-703 (2007).

[11] Zammarano M., Bellayer S., Gilman J. W., Franceschi M., Beyer F. L., Harris R. H., Meriani S.: Delamination of organo-modified layered double hydroxydes in polyamide 6 by melt prosessing. Polymer, 47, 652662 (2006).

[12] Cai L. F., Mai Y. L., Rong M. Z., Ruan W. H., Zhang M. Q.: Interfacial effects in nano-silica/polypropylene composites fabricated by in-situ chemical blowing. Express Polymer Letters, 1, 2-7 (2007).

[13] Asma Y., Jandro L. A., Issac M. D.: Processing of clay-epoxy nanocomposites by shear mixing. Scripta Materialia, 40, 81-86 (2003).

[14] Vaia R. A., Ishii H., Giannelis E. P.: Synthesis and properties of two dimensional monostructures by direct intercalation of polymer melts in layered silicates. Chemical Materials, 5, 1694-1696 (1993).

[15] Lan T., Pinavaia T. J.: Clay-reinforced epoxy nanocomposites. Chemical Materials, 6, 2216-2219 (1994). 
[16] Bokobza L.: Reinforcement of elastomeric network by fillers. Macromolecule Symposia, 171, 163-170 (2001).

[17] Xie W., Gao Z., Pan W-P., Hunter G., Singh A., Vaia R.: Thermal degradation chemistry of alkyl quaternary ammonium montmorillonite. Chemical Materials, 13, 2979-2990 (2001).

[18] Le Pluart L., Duchet J., Sautereau H., Gérard J. F.: Surface modification of montmorillonite for tailored interfaces in nanocomposites. Journal of Adhesion, 78, 645-662 (2002).

[19] Boukerrou A., Duchet J., Fellahi S., Sautereau H.: Processing of mica/epoxy nanocomposites by ultrasound mixing. Journal of Applied Polymer Science, 105, 1420-1425 (2007).
[20] Wang Z., Pinnavaia T. J.: Hybrid organic-inorganic nanocomposites/exfoliation of magadiite nanolayers in an elastoleric epoxy polymer. Chemical Materials, 10, 1820-1826 (1998).

[21] Wang M. S., Pinnavaia T. J.: Clay-polymer nanocomposites formed from acidic derivatives of montmorillonite and an epoxy resin. Chemical Materials, 6, 468474 (1994).

[22] Lopez-Manchado M. A., Herrero B., Arroyo M.: Organoclay-natural rubber nanocomposites synthetized by mechanical and solution mixing methods. Polymer International, 53, 1766-1772 (2004).

[23] Chow W. S., Mohd Ishak Z. A.: Mechanical, morphological and rheological properties of polyamide 6/ organo-montmorillonite nanocomposites. Express Polymer Letters, 1, 77-83 (2007). 